\title{
Vocabulary Mastery in University Students: a Study on EFL Context
}

\author{
Hluing Meung ${ }^{1}$, Myet Htut $^{1}$
}

${ }^{1}$ Education Department, Yangon University of Education, Myanmar

Received: November 15, 2021

Revised: December 16, 2021

Accepted: December 27, 2021

\begin{abstract}
This article discusses strategies for increasing the vocabulary of university students. Knowledge the value of students' vocabulary skills and understanding in order to assist student abilities in all elements of the English language The purpose of producing this essay is to improve one's ability to communicate verbally and in writing. Skills such as listening, speaking, reading, understanding, and writing are all mentioned. This is because the four abilities are one and the same entity; we cannot separate them, yet they may be recognized from one another.
\end{abstract}

Keywords: Vocabulary, Speaking, Writing

\section{Introduction}

Students' degree of knowledge is determined by their ability to acquire new vocabulary. Consequently, pupils' overall learning achievement is influenced by their ability to absorb language in an acceptable way. There are several hurdles that students must overcome in order to learn and understand vocabulary, as well as a number of elements that make it difficult to expand one's vocabulary and comprehend the meaning of a new word. Students' lack of vocabulary skills may be attributed to a variety of issues, including the seldom use of the vocabulary they know, a lack of initiative or interest in learning. However, by adopting certain new habits, such as modifying learning patterns, this can be remedied. When learning English, the most essential thing to remember is that vocabulary is the most crucial element that will boost one's confidence in using the language.

Generally speaking, increasing pupils' vocabulary will help them in all parts of their English abilities, including speaking, writing, and listening skills. In order for students to develop solid vocabulary skills while also restoring their confidence in language learning, it is necessary to implement learning habits or patterns such as keeping vocabulary notes and searching for appropriate strategies to help learning vocabulary.

When it comes to human existence, language is a communication instrument that has a significant impact on increasing the overall quality of all elements of social life. Consequently, vocabulary should not be regarded a less significant skill to master since acquiring vocabulary offers key benefits, such as enhancing students' self-confidence and capacity to compete, as a result of the process of learning it. Knowledge the value of students' vocabulary skills and understanding in order to assist student abilities in all elements of the English language

\section{Vocabulary}

Vocabulary is regarded to be an important component of a language, particularly in the process of learning a foreign language, since the more one's knowledge of vocabulary, the greater one's ability to recite the phrases, clauses, and sentences. Improving student abilities, one of which is vocabulary development, which is a critical component of learning English as a second language. When it comes to acquiring other languages, particularly English, vocabulary (vocabulary) is very critical to success. The term "vocabulary" may be defined as a collection. 
of terms that someone can understand (Herlina, 2015). The definition of vocabulary given by Zhao and Lornkla (2019) is: "the whole pool of words relating to a branch of knowledge or known by a person."

When it comes to studying the English language, vocabulary is essential in the process of teaching and learning the language. The development of pupils' vocabulary is the cornerstone of their ability to comprehend what they are being taught. As a result, studying vocabulary in an appropriate manner contributes to kids' overall learning achievement in the classroom. Vocabulary becomes very significant since it is the most important tool in the creation of sentences necessary to be able to talk fluently, not only in terms of speaking but also in terms of comprehending a text or whatever it is that is in the language of the English language. Learning a new vocabulary is particularly important for success in order to grasp the language well, talk more effectively, or write well; it is predicted that learners will need to improve their vocabulary by around 1000 words every year (Bergmann, 2005).

By learning vocabulary, we may also learn other skills like as reading, listening, speaking, and writing much more quickly and effectively. Learning new language will also have an impact on our confidence, which will grow as we get more bold in speaking English to others around us, so that it becomes a habit and further improves our capacity to communicate. In addition to increasing our vocabulary, we will progressively learn to grasp and master grammar on our own. This is because vocabulary is the smallest unit in English that supports abilities in learning to speak and write the English language.

A vocabulary is more than just a collection of words that we have memorized and understand their meaning; it is also the process of learning how to organize these words (Oxford \& Scarcella, 1994; Nation \& Meara, 2010; Horst, 2005). In the absence of a sufficient vocabulary, pupils not only have trouble communicating, but they may perhaps be unable to speak at all. Furthermore, students will have difficulty obtaining information and controlling their technological devices if they do not comprehend the terminology and grammar used in the course.

In producing the article "Ways to Improving Student Vocabulary," the author's goal is to help students improve their language abilities, both verbally and in writing. Skills such as listening, speaking, reading, understanding, and writing are all mentioned. This is because the four abilities are one and the same entity; we cannot separate them, yet they may be recognized from one another. In order to be considered successful in English proficiency, a one must be able to communicate thoughts and views effectively in English while also using appropriate grammar and writing techniques, as well as be able to speak and comprehend the language fluently (Cowan, 2008; Oscarson, 2009). This demonstrates that students studying English are primarily learning to utilize the language in both oral and written communication in order to be active and successful communicators (Khayati \& Hadi, 2021; Yunus \& Salehi, 2012; Ellery, 2008). By strengthening students' vocabulary abilities, it is also possible to develop their selfconfidence and bravery in speaking English, which they can then use in their daily lives to communicate with both local and international people. To the extent that technology can make it simpler for us to get information and to do duties and other activities that are performed in English, it should.

There are a variety of issues and reasons that contribute to kids' difficulty with language, including the following: Understanding tough-level language is becoming difficult. The birth of a feeling of maleness in one's own self, as well as the ability to remember and comprehend terminology In ordinary life, vocabulary (while speaking in English) is seldom used (Akmal et al., 2020). Based on some of the problem ideas and factors mentioned above, it can be explained that there are four ways to understand vocabulary: (1) Form is studying, listening and repeating, listening for specific phonological information (consonants, vowel sounds, syllable sources, 
stress patterns), looking at or observing the written for shape, first and last letters, letters clusters, spelling, noticing grammatical information, and copying and organizing; (2) Content is studying, listening and repeating, listening for specific phonological (2) Pronunciation is also known as pronunciation in English or pronunciation in the English language. Word meaning, as we all know, refers to the process of understanding the meaning of vocabulary and how it links to other vocabulary and ideas that are related to the subject matter.

Usage is the process of learning how to use vocabulary (vocabulary) in its own right, as well as in the context of other situations (Azar, 2007; Yunus \& Salehi, 2012). The application of new habits, such as creating a note about vocabulary, for example remembering 20 vocabulary words every day and beginning to use them in conversation and writing, may help to reduce some of the elements that make pupils difficult in terms of vocabulary, such as feeling sluggish. Gradually, we will be able to minimize our sense of maleness in ourselves by incorporating certain new behaviors into our daily routines that will continue to assist our capacity to communicate effectively in English. One of the most common difficulties that other students have is that it is difficult for them to comprehend new or high-level terms since they do not often use or study this terminology. When instructors are asked for a solution, they typically suggest that students find up the definition of the term and begin using it regularly in speech and writing. Aside from remembering and understanding the meaning of a word, knowing how to pronounce a word correctly is also extremely crucial to master. It is possible to begin by listening to music or watching news stations from other countries.

\section{Conclusion}

The debate and breakdown of information on how to build up and add to the knowledge of students to city vocabulary may be concluded on the basis of the conclusion that vocabulary acquisition is the foundation of the most fundamental level of student comprehension. As a result, acquiring vocabulary via the use of an appropriate strategy leads to increased student learning success overall. A good vocabulary is essential since it is the primary tool for putting together phrases and speaking fluently. This is true not just for speaking but also for interpreting material, such as words per word, sentences per sentence, and paragraphs in English, which are all crucial skills. It is necessary to demonstrate how vocabulary plays a significant part in the process of learning English due to the fact that vocabulary is a crucial component of the English language. The objective of this article is to be able to assist the abilities of students and persons who are learning English to communicate effectively in speaking, listening, and writing situations. Some issues that arise often may be resolved by using and practicing strategies and techniques for comprehending vocabulary in English so that it becomes a regular habit

\section{References}

Akmal, S., Rasyid, M. N. A., Masna, Y., \& Soraya, C. N. (2020). EFL learners' difficulties in the structure and written expression section of TOEFL test in an Indonesian university. Englisia: Journal of Language, Education, and Humanities, 7(2), 156-180.

Azar, B. (2007). Grammar-Based Teaching: A Practitioner's Perspective. Tesl-ej, 11(2), n2.

Bergmann, B. R. (2005). The Social Factors: Births, Schools, Divorces, Ideas. In The Economic Emergence of Women (pp. 25-40). Palgrave Macmillan, New York.

Cowan, R. (2008). The teacher's grammar of English with answers: A course book and reference guide. Cambridge University Press.

Ellery, K. (2008). Assessment for learning: a case study using feedback effectively in an essaystyle test. Assessment \& Evaluation in Higher Education, 33(4), 421-429. 
Herlina, H. (2016). The Effect of Interest in Reading on Mastery of English Vocabulary with Fifth Grade Elementary Students. Studies in English Language and Education, 3(2), 188-202.

Horst, M. (2005). Learning L2 vocabulary through extensive reading: A measurement study. Canadian Modern Language Review, 61(3), 355-382.

Khayati, M., \& Hadi, M. S. (2021). Explicit Vocabulary Instruction with English Language Learners: a Charade Game. English Language in Focus (ELIF), 3(1), 39-48..

Nation, P., \& Meara, P. (2010). Vocabulary. An introduction to applied linguistics, 34-52.

Oscarson, A. D. (2009). Self-Assessment of Writing in Learning English as a Foreign Language: A Study at the Upper Secondary School Level. Goteborg Studies in Educational Sciences 277.

Oxford, R. L., \& Scarcella, R. C. (1994). Second language vocabulary learning among adults: State of the art in vocabulary instruction. System, 22(2), 231-243.

Yunus, M. M., \& Salehi, H. (2012). The effectiveness of Facebook groups on teaching and improving writing: Students' perceptions. International journal of education and information Technologies, 1(6), 87-96.

Yunus, M. M., \& Salehi, H. (2012). The effectiveness of Facebook groups on teaching and improving writing: Students' perceptions. International journal of education and information Technologies, 1(6), 87-96.

Zhao, M., \& Lornklang, T. (2019). The Use of Picture Word Inductive Model Focusing on Chinese Culture to Promote Young Learners' English Vocabulary Acquisition. Advances in Language and Literary Studies, 10(4), 105-111 